\title{
Os infopoemas de Wlademir Dias- Pino: considerações tecnopoéticas ${ }^{1}$
}

\author{
Vera Casa Nova \\ Universidade Federal de Minas Gerais
}

Resumo: Este artigo mostra o desenvolvimento do Poema Processo de Wlademir Dias-Pino sob a forma de infopoemas. Trata-se de um novo gênero em literatura, em que o poeta desconstrói as palavras pela imagem, a partir de uma coleção de imagens chamada Enciclopédia Visual.

Palavras-Chave: Infopoema, Enciclopédia Visual, Poema Processo.

\begin{abstract}
Que importa quem fala? Nessa indiferença se afirma o princípio ético, talvez o mais fundamental, da escrita contemporânea. O apagamento do autor tornou-se desde então para a crítica, um tema cotidiano. Mas o essencial não é constatar uma vez mais o seu desaparecimento; é preciso descobrir, como lugar vazio - ao mesmo tempo indiferente e obrigatório-, os locais onde sua função é exercida.

Foucault. O que é um autor, 1968.
\end{abstract}

1. Uma versão desse texto foi publicada no site da Revista Eletrônica Sibila: Poesia e Cultura. Disponível em: <http://www.sibila.com.br/index.php/ critica/909-os-infopoemas-de-wlademir-dias-pino $>$. 


\title{
O Pós-Processo
}

\begin{abstract}
A literatura encontrou também o seu lugar no meio eletrônico, e isso já não é mais novidade. Ao lado de outras artes dentro da história dos eventos e das ideias, o poema entrou em nova fase. Feito ou não com palavras, surge diante de nossos olhos ainda perplexos com os avanços tecnológicos, via computador, seu lugar nos sites e blogs específicos de poesia, e negociando semioticamente com outras artes parceiras vai se transformando.

Modalidades eletrônicas de apresentação de textos literários mostram que a competência literária não repousa mais numa formação unívoca, mas numa multiplicidade de técnicas e a constatação de uma pluralidade de usos que podem se apropriar de uma mesma técnica.

Alguns artistas se mostraram e se mostram avessos a aderir a outros suportes, que não sejam as páginas de um livro. Mas do poeta exige-se nova postura: relacionar-se com a tecnologia que avança rapidamente.

Diana Domingues nos diz que "em todas as épocas, os meios e linguagem advindos de descobertas científicas renovaram práticas e teorias em suas implicações artísticas, estéticas, filosóficas, antropológicas, educacionais, políticas e econômicas". E pergunta: "Quão contemporânea é a arte contemporânea quando o computador invade o cotidiano?"

Inovador em sua época com o Poema Processo (contemporâneo do Poema Concreto), Wlademir Dias-Pino, poeta gráfico por natureza, adere aos infopoemas, utilizando o meio digital em sua produção.

Modifica-se o modo de criação, exibição, fruição de sua poética visual, via computação gráfica. Com seu arquivo da Enciclopédia Visual, o poeta se recoloca à frente de uma nova (?) poética que desdobra a arte do Processo. Outra cartografia. Outras tipologias.

Contemporâneo das chamadas estéticas informacionais dos anos de 1960 e 1970 (Moles e outros), Wlademir Dias-Pino, juntamente com sua parceira Regina Pouchain, produz imagens, numa proliferação contínua de experimentações. Combinam-se cores, texturas a partir de programas com suas ricas variáveis, afetando o universo de Gutemberg do texto.

O hibridismo de textos poéticos e imagens ou de somente imagens autopoéticas chama a nossa atenção para o diálogo entre as artes. Advindo das
\end{abstract}

2. DOMINGUES. Arte, ciência e tecnologia, p. 25. 
técnicas de colagem e montagem das Vanguardas do início do século XX, esse momento marca um outro tipo de abstração.

Lembra Mondrian no trabalho com o espaço e segue as linhas de Klee, Malevitch, Boccioni ou Balla, para citar somente alguns pintores que se filiam ao futurismo ou ao Dada.

As imagens se desdobram em imagens. Na edição com que trabalho para esse artigo, a mesma que foi apresentada no Espaço Oi (RJ), os poetas Wlademir Dias-Pino e Regina Pouchain propiciam escolhas, seleção (formas de interatividade) de textos e imagens, que o leitor/espectador sofre, parece ser um complexo multidimensional e intrincado de processos de experiência poética. O que nos leva a crer que no ato de recepção o leitor não busque o significado ou a mensagem que constumeiramente tenta ter das imagens e textos que lê, mas vai aos poucos construindo seus sentidos.

Nessa transformação na artemídia, Ryszard W. Kluszczynski, em seu artigo "Do filme à arte interativa: transformações na artemídia" afirma que

Da perspectiva contemporânea, podemos até observar uma lógica sui generis no desenvolvimento de formas, atitudes, conceitos e teorias que compreendem o processo que vai do neovanguardista (happening, conceitualismo, Fluxus etc.) ao paradigma atual da cultura multimídia interativa, digital, eletrônica. ${ }^{3}$

Mesmo ainda não sendo inteiramente interativos, esses poemas - os três mil Contrapoemas (poemas sem palavras) abstratos e os dois mil Anfipoemas (poemas geométricos com a utilização das palavras luz e cor) - constituem e apresentam algum tipo de interação perceptual e cognitiva do leitor/espectador.

Os contrapoemas, segundo Wlademir Dias-Pino e Regina Pouchain, têm como peculiaridades básicas tratar "o térmico e os processos de compreensão como elemento retardador de supervelocidades, para existir então, a possibilidade de leitura mecânica do cérebro humano". "Enquanto o poema Concreto trabalhou com a concreção, nós queremos a compressão que arquiva mais, em menos espaço." ${ }^{4}$

3. KLUSZCZYNSKI. Do filme à arte interativa: transformações na artemídia, p. 219.

4. Folder de divulgação da Exposição Oi Futuro, realizada no Rio de Janeiro em novembro de 2008. 
Enquanto os anfipoemas são poemas que expandem a letra, o verso, o traço em cores e luz: convém lembrar, o prefixo anfi- vem do gr. amphi $=$ em volta, de ambos os lados, em torno de, em meio a, entre, através de, etc., os contrapoemas fazem o movimento da imagem em suas múltiplas possibilidades gráficas.

Nessa poética experimental lítero-gráfica, os poemas em tela exercitam disjunções entre letra e imagem e compõem um todo em que as partes se deslocam infinitamente. Do poema de palavras ao poema-imagem. Palavra e imagem deslocam-se de seu lugar de origem para exercitarem-se em experiências-limites. Fora da escrita, fora da fonte subjetiva de enunciação bem como do enunciado e "livre de qualquer centro".

Os contrapoemas apontam para o presente ou futuro da arte digital. O movimento faz parte das mudanças ópticas que cada slide apresenta. Pinturas cinéticas, imagens produzidas por programa anterior ao computador. Transformações radicais das imagens, e também do conceito de representação - imagens que deixam de ser o antigo objeto óptico do olhar para converterem-se em imagerie (incessante produção de imagens).

Annateresa Fabris cita Renaud quando ele aponta para "o novo estatuto da imagem e o que é possível produzir nos terrenos da estética e da arte".

Parece-me que os contrapoemas de Wlademir Dias-Pino e Regina Pouchain vão em direção a uma estética do processo que se impõe sobre o objeto. Desdobramentos, versões, contraestilo das obras Ave e Solida. Como nos lembra Clemente Padin,

lo nuevo necesita de nuevos conceptos para ser definido y asumido como "saber de la realidad" en tanto no se extrae del "caos" o del "no ser". Esos nuevos conceptos hay que "crearlos", ya que, aunque pre-existen en los objetos son "no conocidos hasta ese momento". Sólo existen socialmente cuando son nombrados, es decir, cuando adquieren un "formato de palabra" que representa aquel correlato objetual descubierto.

5. FOUCAUlT. O pensamento do exterior, p. 219

6. RENAUD citado por FABRIS. A imagem hoje: entre passado e presente, p. 201.

7. PADIN. Apresentação, citado por NAVAS. A aventura visual de WDP, p. 47. 
Arte gráfica, arte literária? Os conceitos se transformam e estão sujeitos às transformações históricas. Trata-se de obra de natureza processual, que enfatiza sua qualidade de não acabada (tanto que Dias-Pino e Pouchain não terminam os cinco mil poemas), estão sempre produzindo imagens.

Ler essas imagens com paradigmas a que estamos acostumados a ler parece impossível, pois a imagem não se deixa apreender. Trata-se de um modelo mais complexo que leva em conta elementos intrincados de temporalidades heterogêneas de que toda imagem é feita.

"Um poema não se faz com palavras, mas com ideias", diz Dias-Pino. Eis um paradoxo que os contrapoemas parecem explicitar.

Cada imagem grapho-ótica é depositária de formas gráficas, uma ruptura que se estampa e nos toca, nos impressiona. Restam-nos impressões (de coisa grapho-impressa). Não é um gesto de pressão, mas um resultado que é uma marca. "Para que uma impressão de passos se produza enquanto processo, é preciso que o pé se enterre na areia, que o caminhante esteja ali, no próprio lugar da marca a ser deixada."

O mesmo se dá com esses contrapoemas. O trabalho realizado pelo artista é o de imprimir imagens sobre imagens. Como um palimpsesto digital.

Deixar impressões na tela com imagens que vão se apagando na medida em que outras vão se formando. Como o pé na areia. Para que a impressão apareça enquanto resultado é preciso também que o pé se levante, se separe da areia e se afaste para outras impressões que se produzem posteriormente. Agora o caminhante não está mais ali.

De como o poeta responde a nossa época, às invenções técnicas? Abstração? "A arte abstrata tende a apagar os vestígios de autoria na proporção inversa em que as instalações têm necessidade de deixar o rastro de um registro." São as incertezas do opus, como afirma Michel Foucault. ${ }^{10}$

O poeta redefine a relação de espectador com a obra, transformando pensamento e visualidade. Essas imagens - contrapoemas - não visam representar qualquer coisa externa a eles. Designs eletrônicos, complexidade gráfica, eis o que as poéticas experimentais trazem à interface do poeta à máquina.

8. DIDI-HUBERMAN. La ressemblance par contact, p. 309.

9. DIAS-PINO. Carta aberta, citado por NAVAS. A aventura visual de WDP, p. 52.

10. FOUCAUlT. O pensamento do exterior, p. 219 
A poética visual dos contrapoemas apresenta novos parâmetros de arte visual. Desafia-se a teoria. A complexa variedade de formas que são desenvolvidas no processo é infinita. Na obra de arte virtual produzida digitalmente é o processo e a dinâmica que se instalam nessas paisagens virtuais a que a arte gráfica de Dias-Pino nos possibilita ver.

Através de seus contrapoemas, podemos observar que as mudanças no campo da arte, advindas de propostas dos anos 1960/1970, por exemplo, do Poema Concreto, do Poema Processo, entre outros, liberam a palavra para que com ela o poeta a crie sem limites. Jean Baudrillard ${ }^{11}$ nos fala de "autorreprodução ao infinito", "modo fractal de dispersão" etc.

O contrapoema seria assim uma modalidade das poéticas experimentais em que encontramos no limite as mais variadas vertentes paradigmáticas da arte contemporânea (incluindo aí a arte abstrata), realizada através de confluências, superposições dessas vertentes.

Experimentação à parte, os contrapoemas pertencem a um projeto maior - a Enciclopédia Visual - e mantém com ela, a partir desse encontro, um princípio fundamental - não se sabe jamais exatamente no que vai dar. Inesperada, instável e aberta, a forma se revela ao poeta como se o "inconsciente óptico" de que nos fala Walter Benjamin acontecesse, ou um "inconsciente técnico" de que nos fala Huberman ${ }^{12}$ permeasse as imagens mostradas abaixo.

11. BAUDRILLARD. A transparência do mal, p. 9.

12. DIDI-HUBERMAN. La ressemblance par contact, p. 35. 


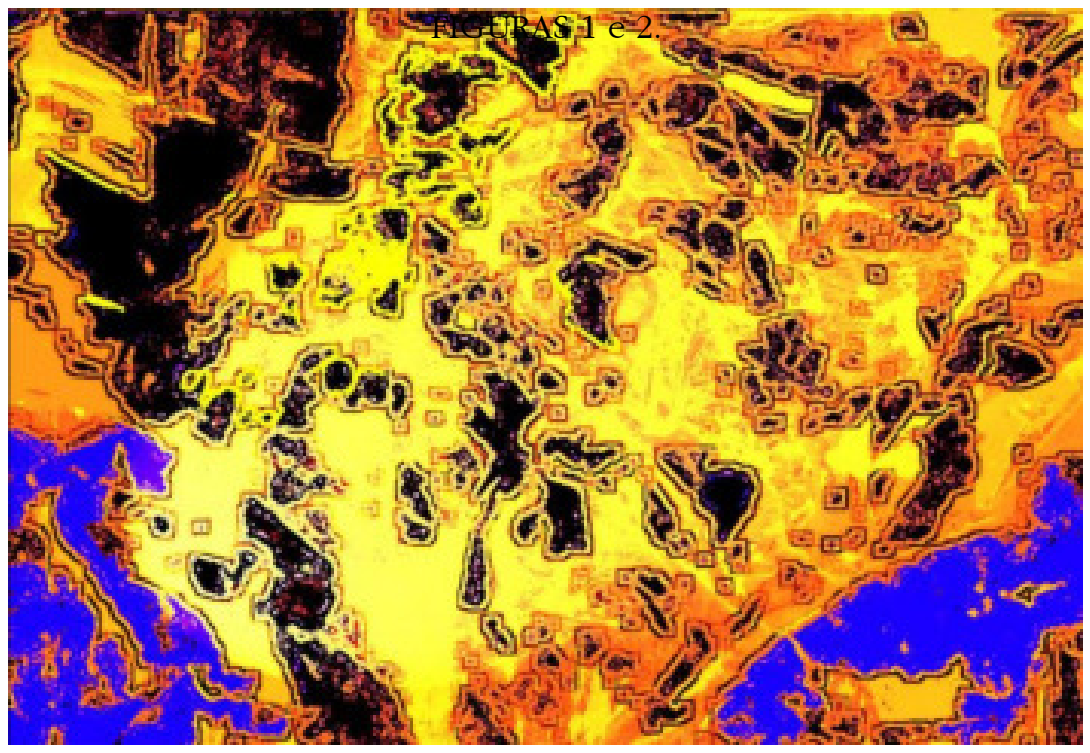

FIGURA 1

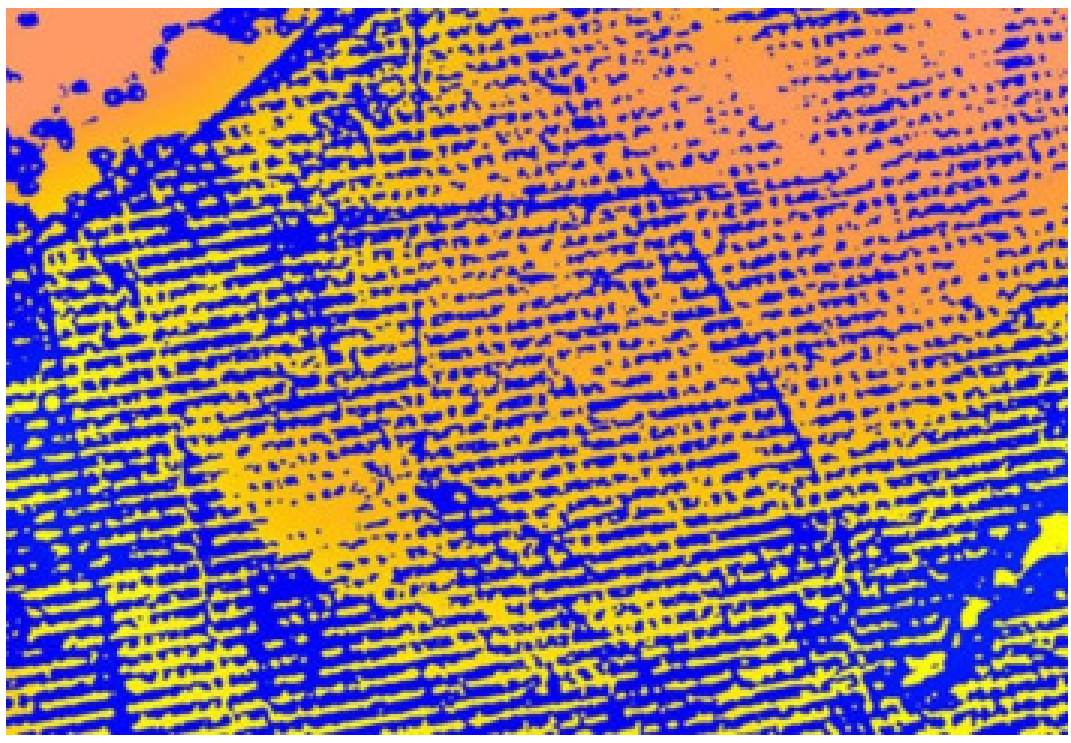

FIGURA 2 


\section{Les infopoèmes de WDP: considérations tecno-poétiques}

Résumé: Cet essai montre le developpement du Poème Procès de Wlademir Dias-Pino sous le forme d'info-poèmes. Ils'agit d'un nouveau genre en littérature où le poete déconstuit les mots par l'image à partir d'une collection d'images appelée Encyclopédie Visuelle.

Mots-clés: Info-Poème, Encyclopédie Visuelle, Poème Procès.

$$
\text { Referências }
$$

BAUDRILLARD, Jean. A transparência do mal: ensaios sobre os fenômenos extremos. Campinas: Papirus, 1990.

DIAS-PINO, Wlademir. Carta aberta. Revista Dasartes, n. 5, set. 2009.

DIDI-HUBERMAN, G. La ressemblance par contact. Paris: Minuit, 2008.

DOMINGUES, Diana (Org.). Arte, ciência e tecnologia: passado, presente e desafios. São Paulo: Itaú-Unesp, 2009.

FABRIS, Annateresa. A imagem hoje: entre passado e presente. In: DOMINGUES, Diana (Org.). Arte, ciência e tecnologia. São Paulo: Itaú-Unesp, 2009. p. 201-206.

FOUCAULT, Michel. O pensamento do exterior. In: Ditos e escritos. Rio de Janeiro: Forense Universitária, 2001. v. 3. p. 219-242.

KLUSZCZYNSKI, Ryszard W. Do filme à arte interativa: transformações na artemídia. In: DOMINGUES, Diana (Org.). Arte, ciência e tecnologia: passado, presente e desafios. São Paulo: Itaú-Unesp, 2009. p. 219-237.

NAVAS, Adolfo Montejo. A aventura visual de WDP. Revista Desartes, Rio de Janeiro, ano 1 , n. 5, p. 47-52, ago.-set. 2009.

PADIN, Clemente. Apresentação. In: ANTONIO, Jorge Luiz. Poesia digital. São Paulo: Navegar; Fapesp, 2010. 